\title{
Boundary maps
}

Counties and unitary authorities in England, 1998 and 2009

NUTS levels 1, 2 and 3 in England, 2008

Unitary authorities in Wales, 2005/Awdurdodau unedol yng Nghymru, 2005

NUTS levels 1, 2 and 3 in Wales, 2008/NUTS lefelau 1, 2 a 3 yng Nghymru, 2008

NUTS levels 1, 2 and 3 in Scotland, 2008

Geographical classifications in Northern Ireland

Police areas, United Kingdom

Health areas, England, 2006

Environment Agency regions, England and Wales, 1996

Regions of the National Rivers Authority, England

Education authorities in England 


\section{Counties and unitary authorities in England, $1998^{1}$ and $2009^{2}$}

1 Hartlepool

2 Middlesbrough

3 Redcar and Cleveland

Stockton-on-Tees

Darlington

6 Halton

7 Warrington

8 Blackburn with Darwen

9 Blackpool

10 East Riding of Yorkshire

11 City of Kingston upon Hull

12 North East Lincolnshire

13 North Lincolnshire

14 York

15 Derby

16 Leicester

17 Rutland

18 Nottingham

19 County of Herefordshire

20 Telford and Wrekin

21 Stoke-on-Trent

22 Luton

23 Peterborough

24 Southend-on-Sea

25 Thurrock

26 Bracknell Forest

27 Reading

28 Slough

29 West Berkshire

30 Windsor and Maidenhead

31 Wokingham

32 Milton Keynes

33 Brighton and Hove

34 Portsmouth

35 Southampton

36 Isle of Wight

37 Medway

38 Bath and North East Somerset

39 City of Bristol

40 North Somerset

41 South Gloucestershire

42 Plymouth

43 Torbay

44 Bournemouth

45 Poole

46 Swindon

(a)

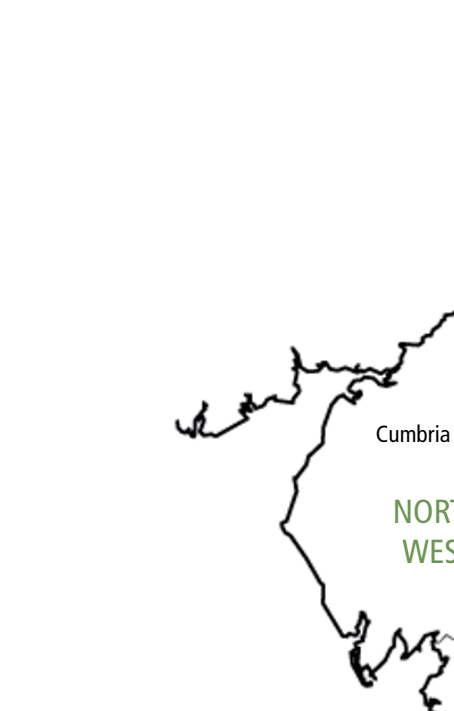

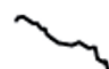

Northumberland

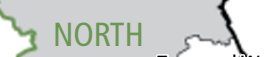

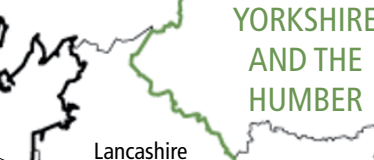

AND THE

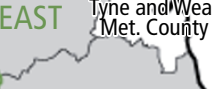

$\left\{\begin{array}{c}\text { West Yorkshire } \\ \text { Met. County }\end{array}\right.$

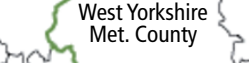

Local government structure post April $2009^{2}$
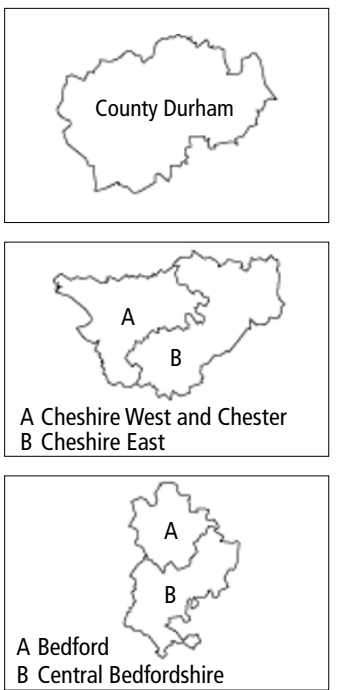

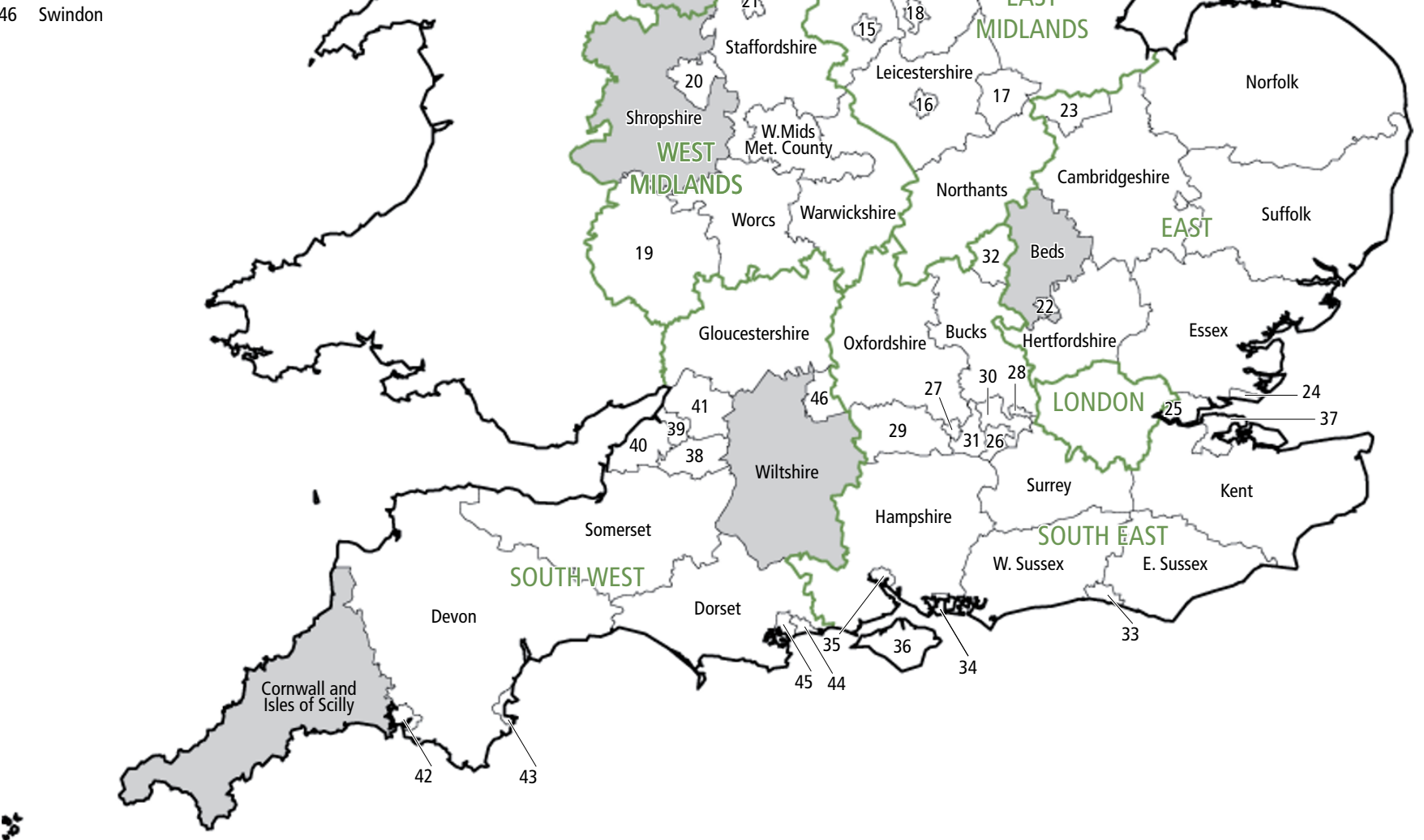

1 Local government structure as at April 1998. See Notes and Definitions online.

2 Areas affected by changes on 1st April 2009 are shaded grey. Four areas: Durham, Cheshire, Bedfordshire, Cornwall and Isles of Scilly had boundary/ name changes at this level and insets show the current structure. The remainder: Northumberland, Shropshire and Wiltshire changed from county to unitary authority status but were otherwise unchanged, these are not inset. Local authority districts as at April 1998 are shown on the maps in the Region and Country Profiles (Section 2) 
NUTS levels 1, 2 and 3 in England,' 2008

\section{NUTS level 3 areas}

1 Tyneside

2 Sunderland

3 Darlington

4 Hartlepool and Stockton-on-Tees

5 South Teeside

6 Blackpool

7 Blackburn with Darwen

8 Sefton

9 Liverpool

10 East Merseyside

11 Greater Manchester North

12 Greater Manchester South

13 York

14 Bradford

15 Calderdale, Kirklees and Wakefield

16 East Riding of Yorkshire

17 Kingston upon Hull, City of

18 North and North East Lincolnshire

19 Barnsley, Doncaster and Rotherham

20 Sheffield

21 East Derbyshire

22 North Nottinghamshire

23 Derby

24 Nottingham

25 South Nottinghamshire

26 South and West Derbyshire

27 Wirral

28 Halton and Warrington

29 Telford and Wrekin

30 Stoke-on-Trent

31 Walsall and Wolverhampton

32 Dudley and Sandwell

33 Birmingham

34 Solihull

35 Coventry

36 Leicestershire CC and

Rutland

37 Leiceste

38 Northamptonshire

39 Peterborough

40 Milton Keynes

41 Buckinghamshire CC

42 Bedfordshire CC

43 Luton

44 Outer London - West and North West

45 Inner London - West

46 Inner London - East

47 Outer London - East and North East

48 Outer London - South

49 Thurrock

50 Southend-on-Sea

51 Medway

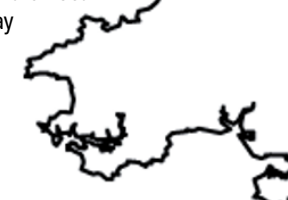

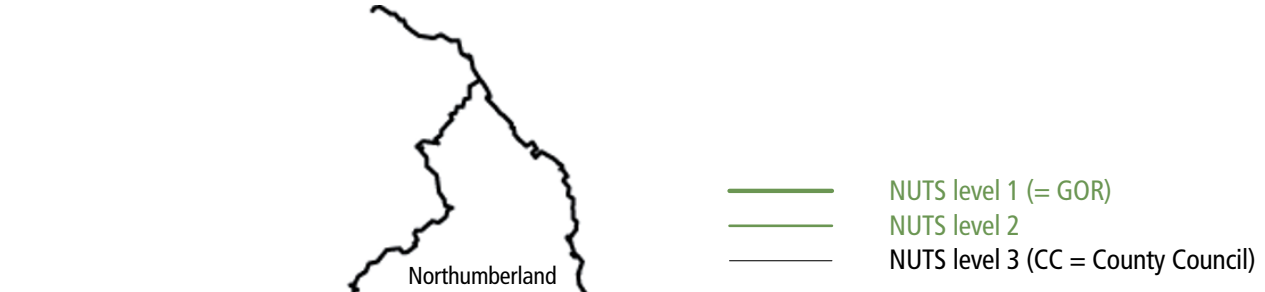

52 Bristol, City of

53 Bath and North East Somerset

North Somerset and South Gloucestershire

54 Swindon

55 Plymouth

56 Torbay

57 Bournemouth and Poole

58 Southampton

59 Portsmouth

60 Brighton and Hove

1 NUTS (Nomenclature of Units for Territorial Statistics) is a hierarchical classification of areas that provides a breakdown of the EU's economic territory. See Notes and Definitions online. 
Unitary authorities in Wales, 2005

Awdurdodau unedol yng Nghymru

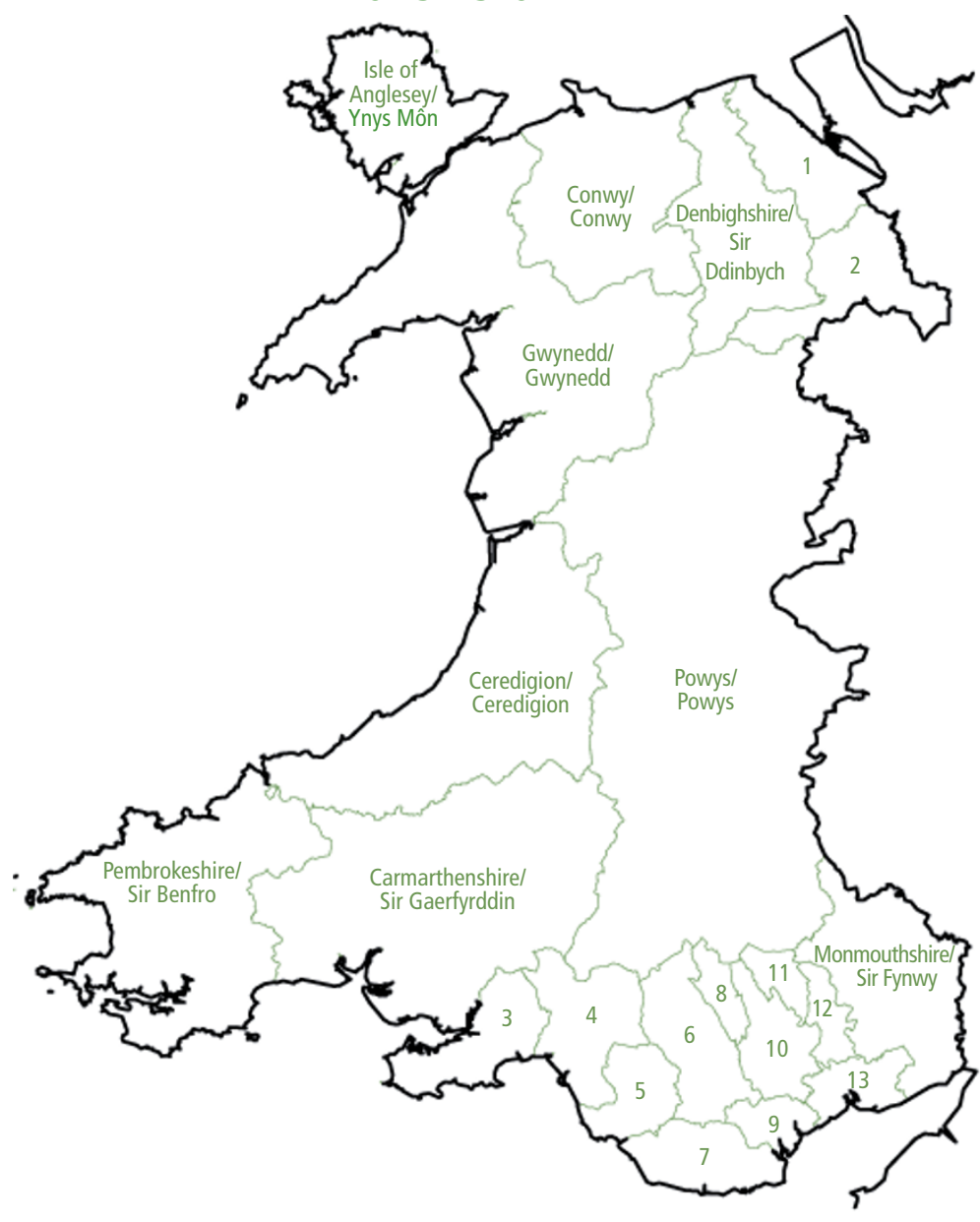

1 Flintshire/Sir y Fflint

2 Wrexham/Wrecsam

3 Swansea/Abertawe

4 Neath Port Talbot/Castell-nedd Port Talbot

5 Bridgend/Pen-y-bont ar Ogwr

6 Rhondda, Cynon, Taff/Rhondda, Cynon, Taf

7 The Vale of Glamorgan/Bro Morgannwg

8 Merthyr Tydfil/Merthyr Tudful

9 Cardiff/Caerdydd

10 Caerphilly/Caerffili

11 Blaenau Gwent/Blaenau Gwent

12 Torfaen/Tor-faen

13 Newport/Casnewydd

NUTS levels 1, 2 and 3 in Wales, 2008

NUTS lefelau 1, 2 a 3 yng Nghymru, 2008

NUTS level 2/NUTS lefel 2

NUTS level 3/NUTS lefel 3
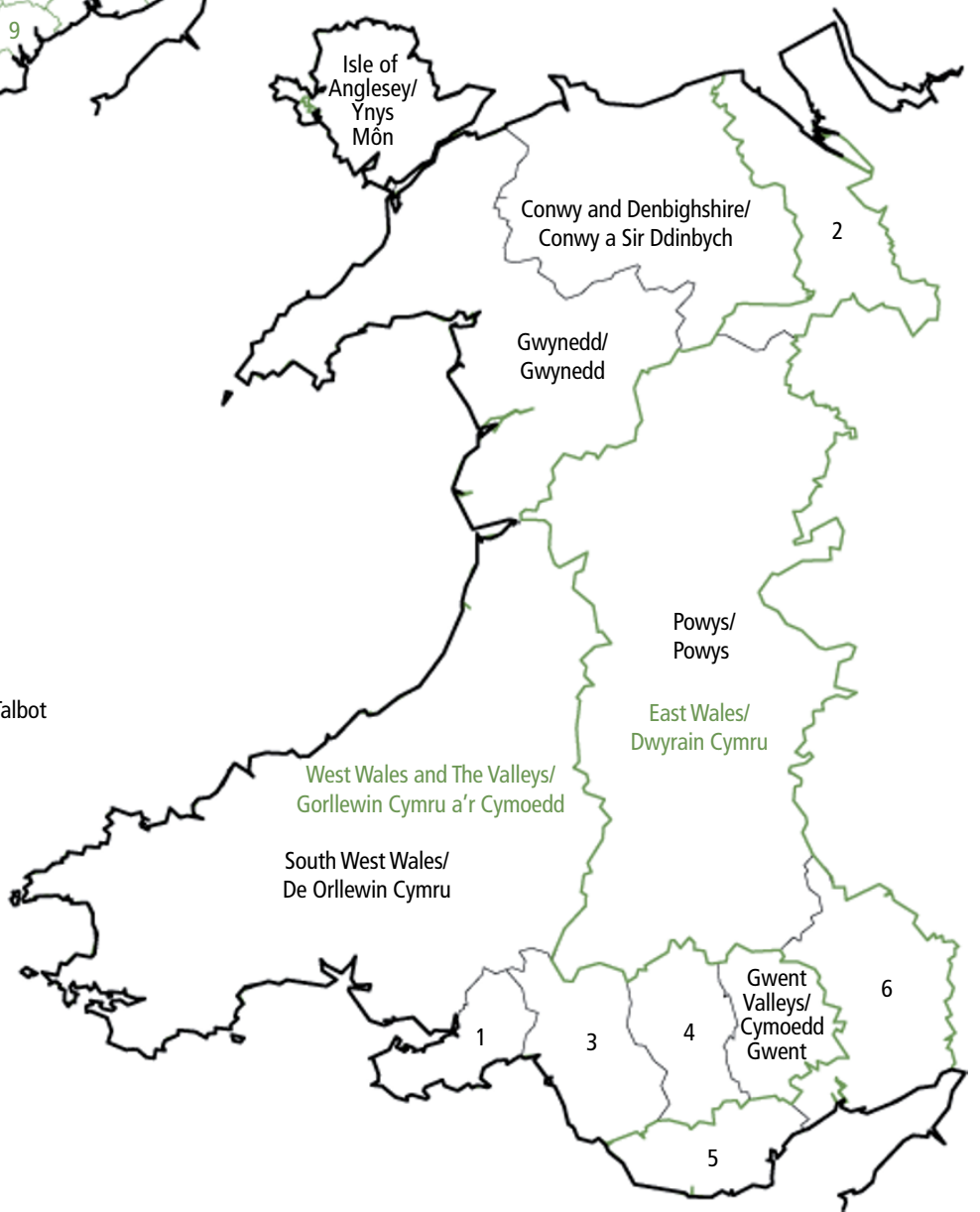

1 Swansea/Abertawe

2 Flintshire and Wrexham/Sir y Fflint a Wrecsam

3 Bridgend and Neath Port Talbot/Pen-y-bont ar Ogwr a Chastell-nedd Port Talbot 4 Central Valleys/Canol y Cymoedd

5 Cardiff and Vale of Glamorgan/Caerdydd a Bro Morgannwg

6 Monmouthshire and Newport/Sir Fynwy a Chasnewydd

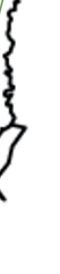

1 NUTS (Nomenclature of Units for Territorial Statistics) is a hierarchical classification of areas that provides a breakdown of the EU's economic territory. The NUTS level 1 area is the whole country. See Notes and Definitions online.

Mae NUTS (Enwau Unedau Tiriogaethol at Ddibenion Ystadegaeth) yn ddosbarthiad hierarchaidd o ardaloedd sy'n darparu dadansoddiad o diriogaeth economaidd yr UE. Yr ardal NUTS lefel 1 yw'r wlad gyfan. Gweler y Nodiadau a'r Diffiniadau ar-lein. 


\section{Councils in Scotland, 1996}

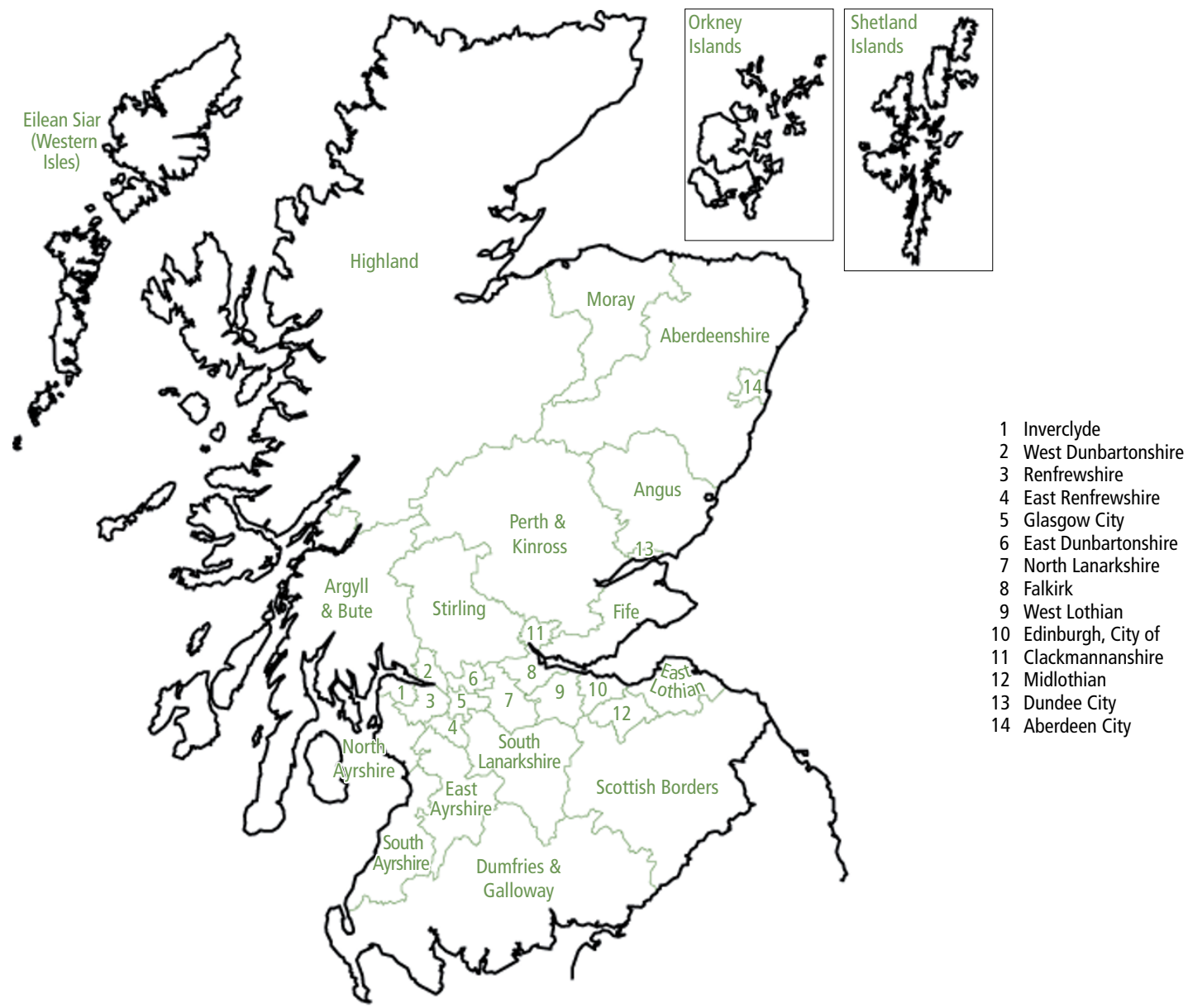

NUTS levels 1, 2 and 3 in Scotland, 2008

NUTS level 2 NUTS level 3

1 Lochaber, Skye \& Lochalsh, Arran \& Cumbrae and Argyll \& Bute

2 Clackmannanshire and Fife

3 East Dunbartonshire, West Dunbartonshire and Helensburgh \& Lomond

4 North Lanarkshire

5 Edinburgh, City of

6 East Lothian and Midlothian

7 Inverclyde, East Renfrewshire and Renfrewshire

8 Glasgow City

9 East Ayrshire and North Ayrshire mainland
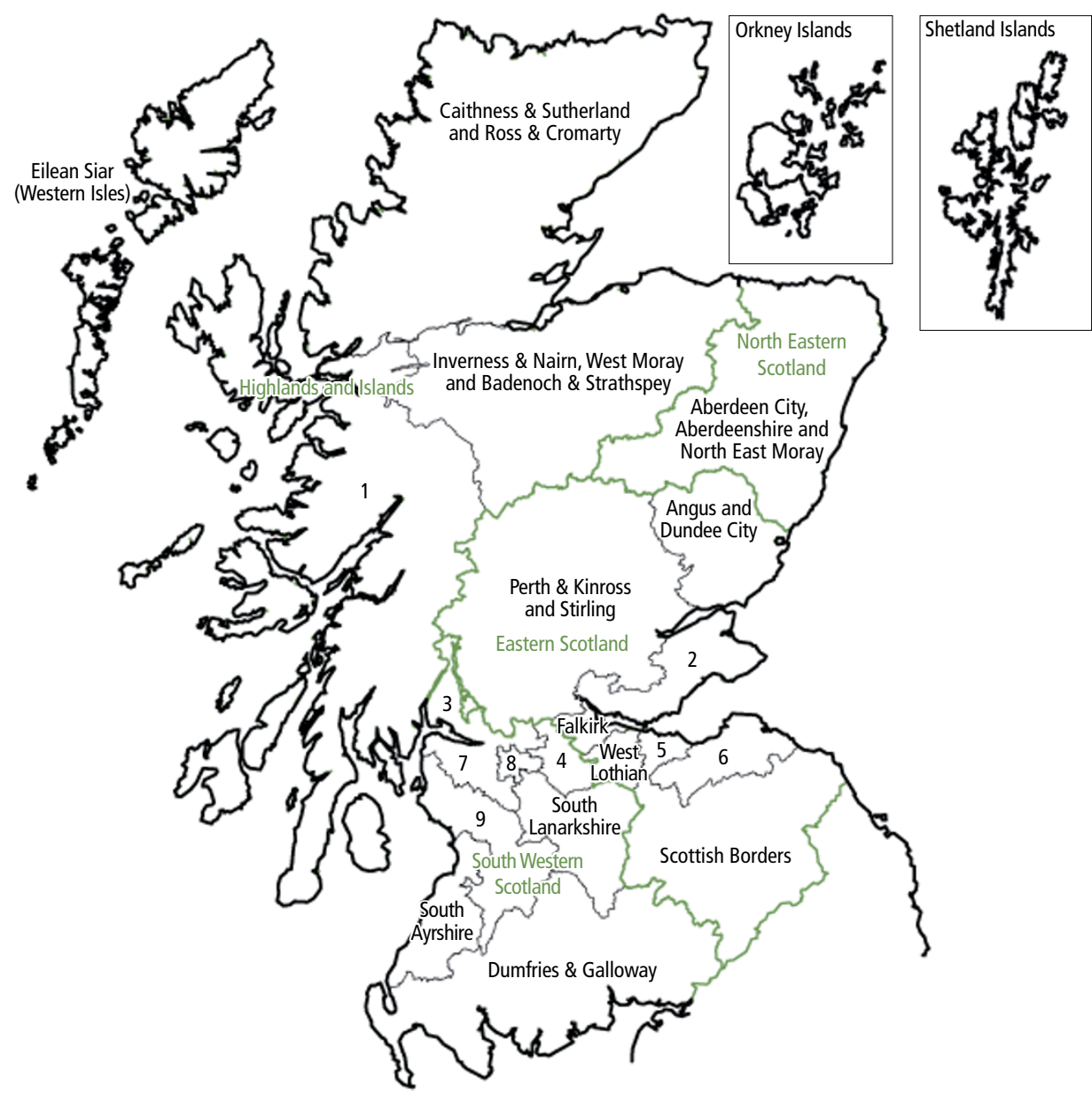


\section{Geographical classifications ${ }^{1}$ in Northern Ireland}

Education and Library Boards, 1992

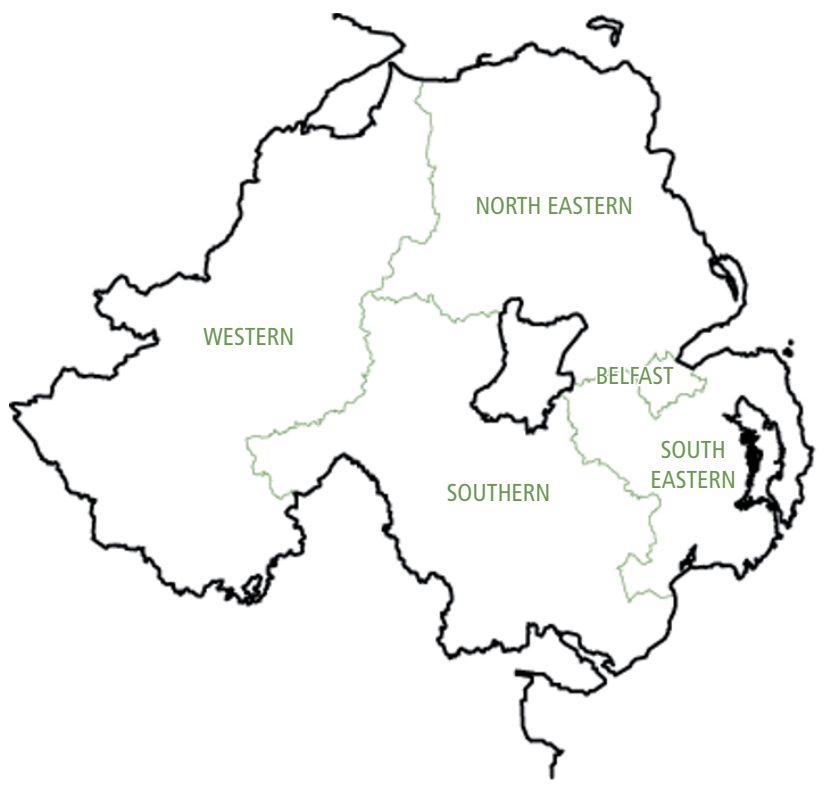

Health and Social Services Boards, $2003^{2}$

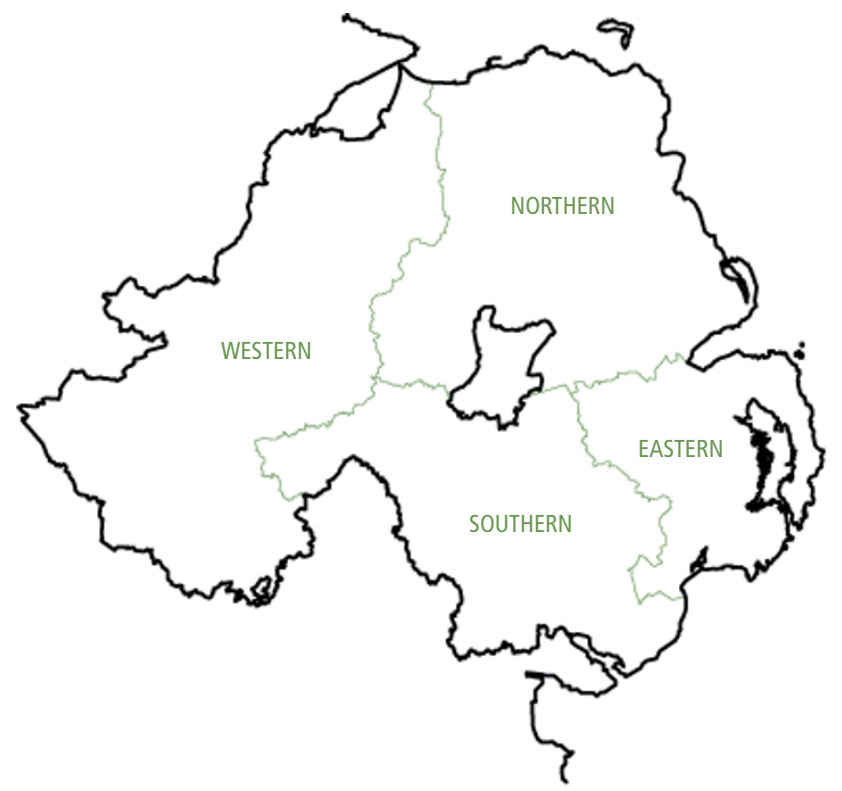

District Councils, 1992

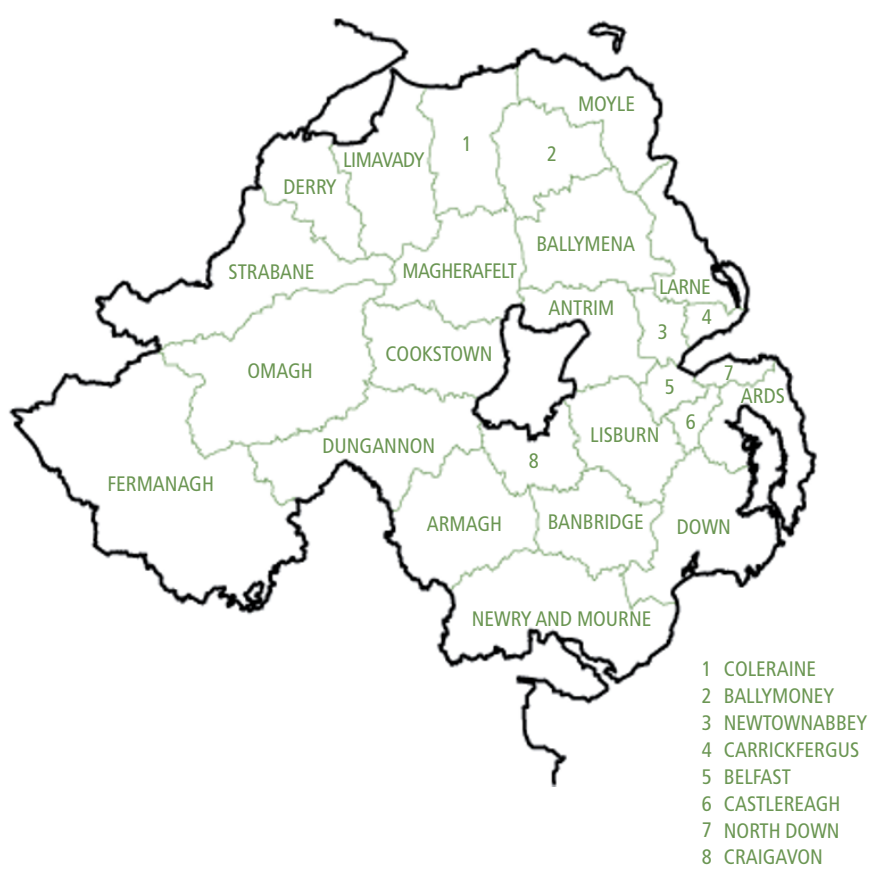

NUTS levels 1, 2 and 3 in Northern Ireland, 2008

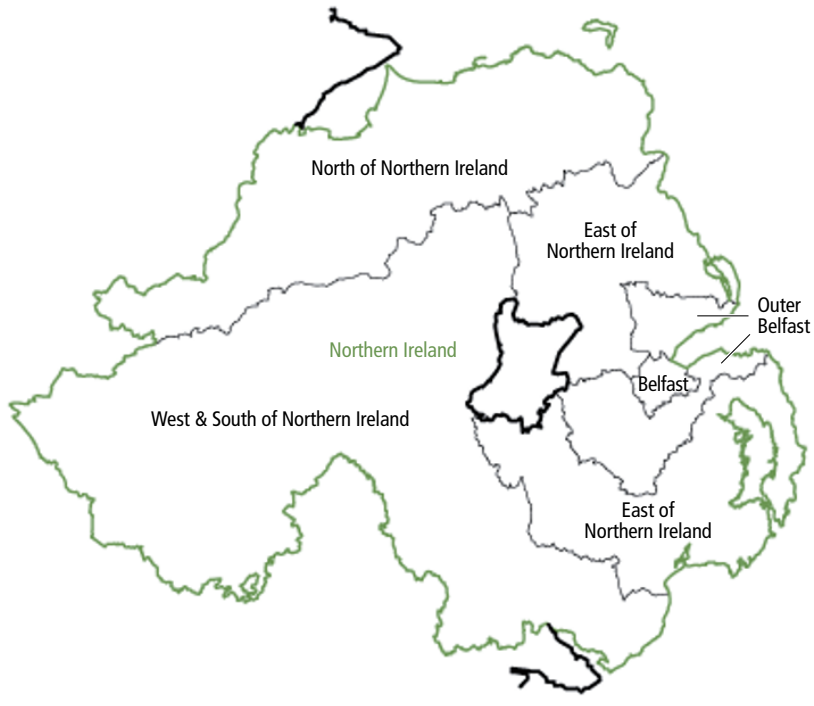

NUTS level 1 and 2 NUTS level 3 


\section{Police areas, United Kingdom}

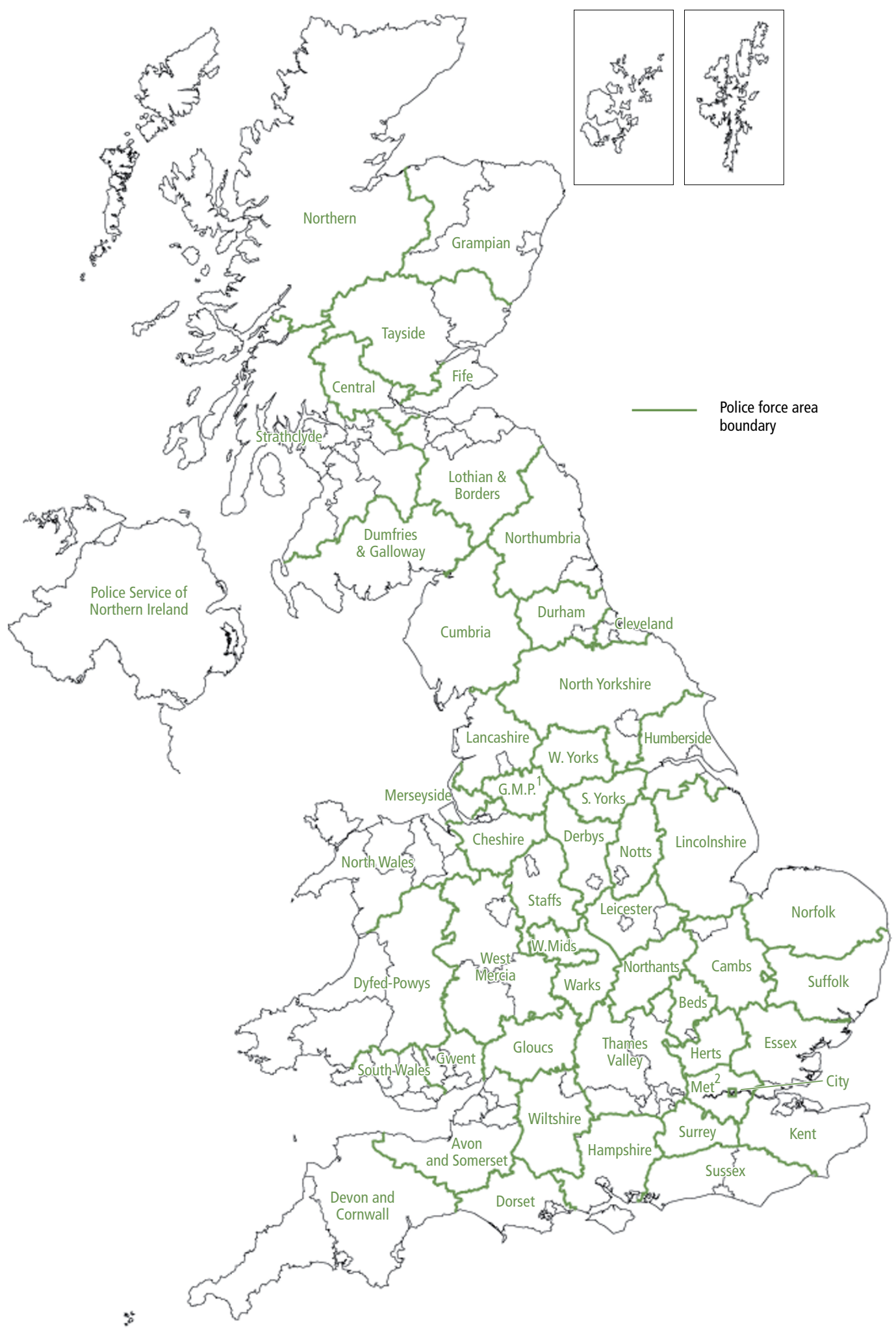


Health areas, England, 2006

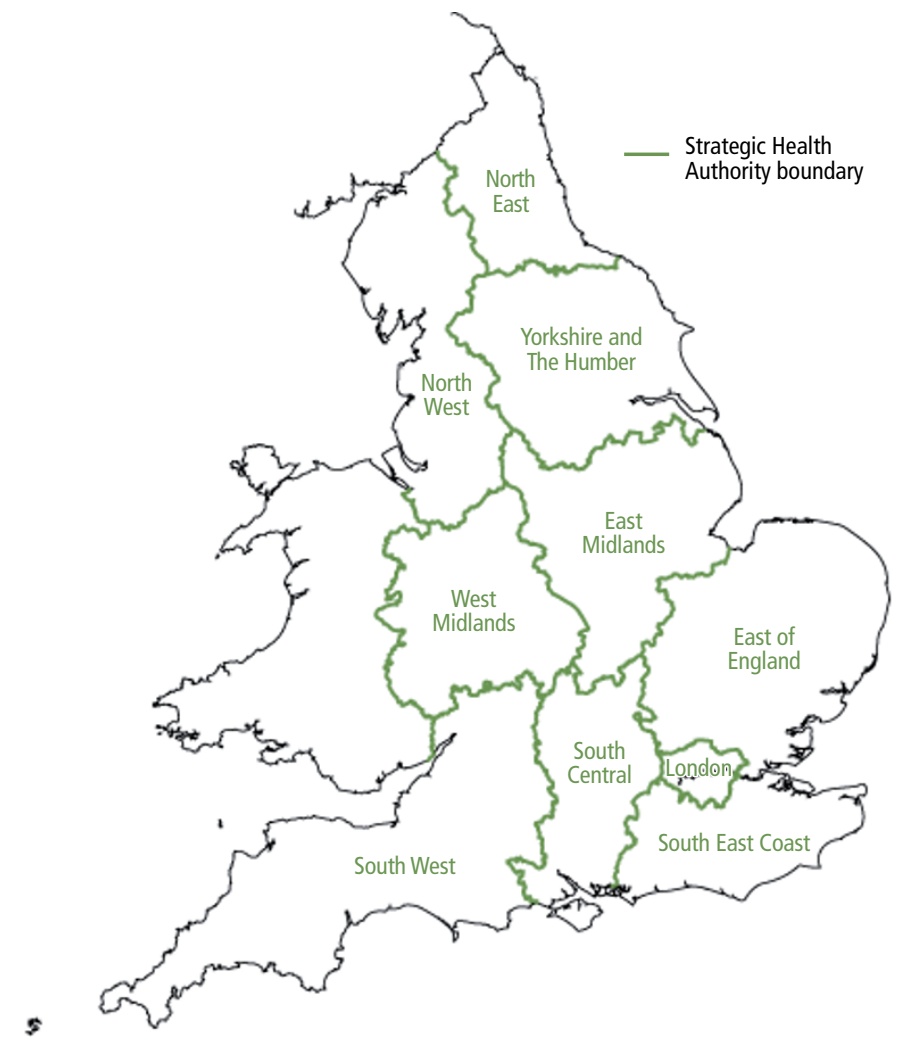

Environment Agency regions, England and Wales, 1996

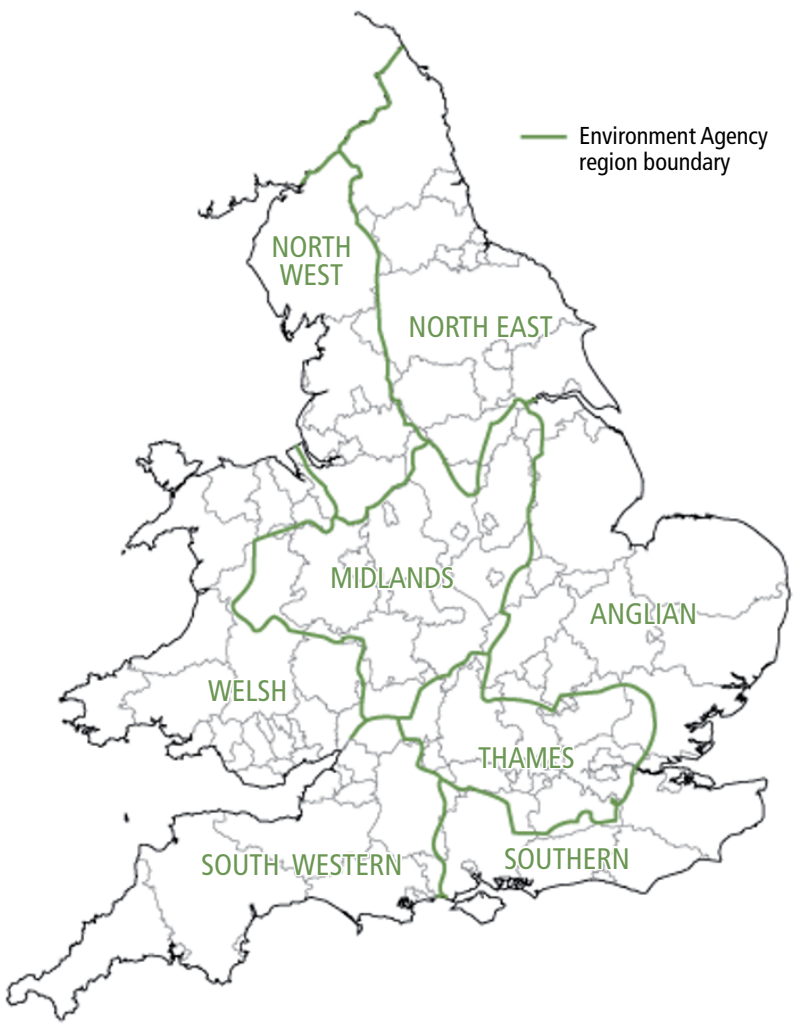

Regions of the National Rivers Authority, ${ }^{1}$ England

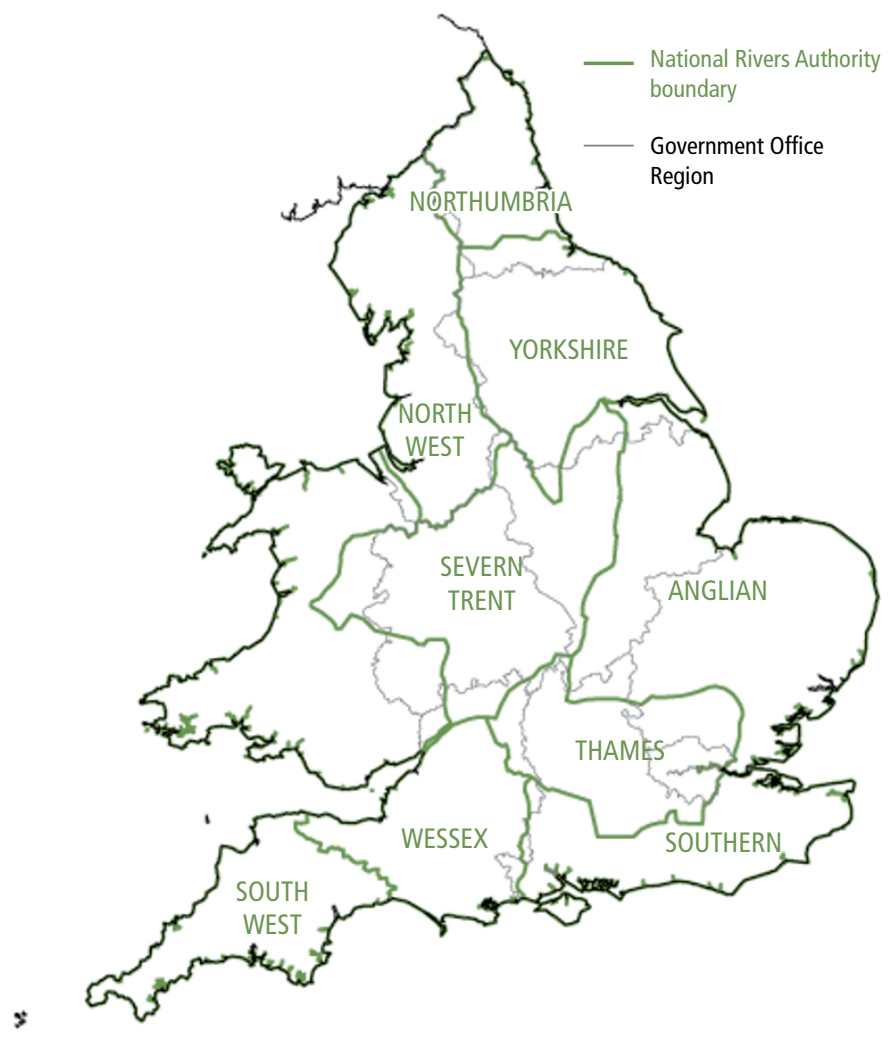




\section{Education authorities in England}

1 North Tyneside
2 Newcastle upon Tyne
3 Gateshead
4 South Tyneside
5 Sunderland
6 Hartlepool
7 Stockton-on-Tees
8 Darlington
9 Middlesbrough
10 Redcar and Cleveland
11 Kingston upon Hull
12 North Lincolnshire
13 North East Lincolnshire
14 Calderdale
15 Kirklees
16 Wakefield
17 Barnsley
18 Sheffield
19 Rotherham
20 Doncaster
21 Derby
22 Nottingham
23 Leicester
24 Rochdale
25 Oldham
26 Tameside
27 Stockport
28 Manchester
29 Bury
30 Blackburn with Darwen
31 Bolton
32 Wigan
33 Salford
34 Trafford
35 Warrington
36 St Helens

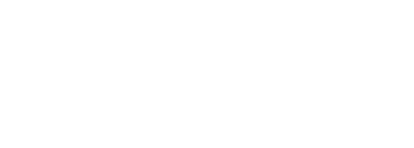

